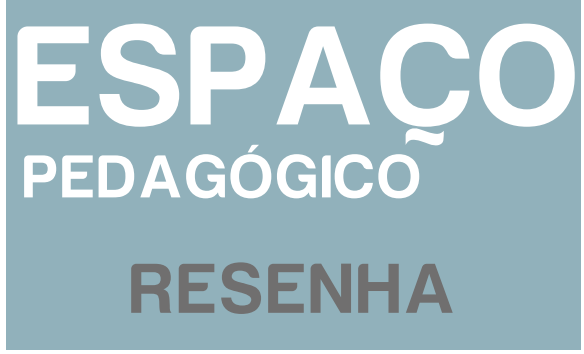




\title{
0 frango de Newton: a ciência na cozinha
}

Ênio Freire de Paula*

Originalmente publicado na Itália em 2013, como Il Pollo di Newton: La scien$z a$ in cucina, a obra do italiano Massimiano Bucchi, professor na Universidade de Trento, tem agora sua versão em português publicada pela Editora da Unicamp. O livro integra a Coleção Meio de Cultura, ${ }^{1}$ organizada pelo Prof. Dr. Marcelo Knobel, a qual completou uma década de existência em 2018 e reúne a tradução de títulos voltados à divulgação científica publicados em diversos países, entre eles: Argentina, Austrália, Espanha e Itália, além de publicações brasileiras.

A problemática da obra - cujo título sugestivo foi um dos responsáveis por a adquirirmos - discute as inovações sociais e tecnológicas envolvidas no avanço da Gastronomia e os eventos históricos - no decorrer da história recente - responsáveis por inter-relacionar a "ciência como culinária e a culinária como ciência", como diz o autor.

Aliás, vale destacar que o momento de publicação desse livro coincide com 0 aumento expressivo da temática gastronômica no contexto nacional. Um desses indícios é sem dúvida o crescimento vertiginoso da oferta de cursos de Gastronomia (tecnólogos e bacharelados) em especial aqueles ofertados em instituições privadas de ensino superior. Comparando os resultados de Rubim e Rejowski (2013) com os de Anjos, Cabral e Hostins (2017) - nos dois estudos, os pesquisadores realizaram levantamentos sobre a oferta de cursos de Gastronomia no país -, a oferta de cursos livres nessa área teve início na década de 1970; em 2016, o país atingiu o número de 151 cursos em funcionamento (grande parte tecnólogos). Aproximadamente a metade deles se concentra nos estados da Região Sudeste, da qual São Paulo reúne 1/3 de toda a oferta nacional. Outro indício é o aumento de atrações culinárias na programação dos canais de TV aberta, a cabo e nos serviços de streaming. Os diversos reality shows culinários, pelos quais cursos na tradicional escola de gastronomia francesa

\author{
Recebido em 20/10/2018 - Aprovado em 24/06/2019 \\ http://dx.doi.org/10.5335/rep.v26i3.9878
}

Doutor em Ensino de Ciências e Educação Matemática na Universidade Estadual de Londrina (UEL). Professor do Instituto Federal de Educação, Ciência e Tecnologia de São Paulo, Campus de Presidente Epitácio (IFSP/PEP), Brasil. ORCID: 0000-0003-0395-4689. E-mail: eniodepaula@ifsp.edu.br 
Le Cordon Bleu (fundada em 1895) figuram entre os prêmios, são representantes do sucesso que a cozinha profissional e seus avanços despertam nos brasileiros.

Contudo, o livro não trata a Gastronomia ou a Ciência isoladamente. As aproximações entre ciência, tecnologia e sociedade, exemplificadas pelas relações humanas com a culinária, a ciência e os avanços tecnológicos, constituem o prato principal da obra.

Organizada em quatro capítulos que, embora sejam curtos, são nomeados com títulos grandes, que nos remetem às obras do medievo, a obra exige fôlego para acompanhar os insights do autor com referência a diversos personagens e períodos históricos. O livro é um deleite aos apaixonados pela História da Ciência e um convite aos leitores interessados nesse campo.

"Entrada, seguida de primeiro prato - a culinária como ciência, a ciência como culinária, de Sócrates à fusão a frio" é o capítulo de abertura que inicia a discussão da problemática. Ao refletir sobre o quadro de um famoso programa de TV italiano chamado "A ciência na cozinha", em que são questionados os processos físicos e químicos ocorridos na preparação de alimentos, deparamo-nos com uma curiosa pergunta: como se faz maionese? É possível que muitos de nós, em algum momento, já tenhamos nos questionado a respeito dos processos de produção de algumas iguarias, posto que muitas vezes nós as compramos já prontas, industrializadas. $\mathrm{O}$ autor retoma diversos eventos e modificações ocorridas no processo de produção dos alimentos a partir do século XVII, que culminaram em técnicas sofisticadas e proporcionaram desconfianças e ceticismo frente aos considerados "novos alimentos", como o extrato de carne, criado pelo químico alemão Justus von Liebig (1803-1873). Prosseguindo na história, somos apresentados a diversas pesquisas - criativas e curiosas -, inclusive algumas ganhadoras do famoso Prêmio Ignobel, ofertado pela revista Annals of Improbable às pesquisas científicas mais excêntricas em cada ano.

"Segundo prato - a ciência do frango" é o capítulo seguinte. O frango, mote de anedotas curiosas e eventos científicos efetivamente ocorridos, é o fio condutor das discussões a respeito do interesse em experiências com esse animal que perpassam os campos de criação (desenvolvimento e aprimoramento de métodos de cria, engorda e armazenamento), preparo (crítica e desvelamento de práticas culinárias difusas, ingênuas e inconsistentes) e experimentação (desenvolvimento de vacinas e cura de doenças), entre os séculos XVII e XXI. Situações envolvem o frango com Francis Bacon (1561-1626), Louis Pasteur (1822-1895), Isaac Newton (1643-1727), os iluministas e a produção Encyclopédie e os episódios da gripe aviária em 2006. O 
caráter acidental de algumas descobertas científicas - a serendipidade -, a realização de experimentos públicos e a visão estereotipada do cientista são problematizados. Ao tratar especificamente da visão pública do cientista, destaca-se o machismo, tão presente no decorrer da História da Ciência (colocando o homem como cientista e a mulher como responsável pelo cuidado com os afazeres domésticos e a culinária), e também a praticamente substituição da iconografia religiosa para a iconografia do cientista, na qual o desinteresse pelos anseios e frivolidades humanos é visto como uma prerrogativa para forjá-la: "É uma iconografia que enfatiza o caráter intelectual e desencarnado do homem de ciência, o seu distanciamento das necessidades materiais e até mesmo da dimensão corpórea" (BUCCHI, 2015, p. 66).

Dentre as seções que integram o segundo capítulo e o seguinte, "Bebidas à parte - cerveja, vinho, café, chá, chocolate e... controvérsias à vontade”, aprofundam-se as discussões no sentido de evidenciar o (des)cuidado (da mídia, dos cientistas e governantes) nas tentativas de elucidar/comunicar os avanços da Ciência. $\mathrm{O}$ autor discute e problematiza a percepção pública de ciência, assunto intrinsicamente associado à divulgação científica enquanto campo de investigação. No Brasil, a esse respeito, podemos destacar os trabalhos de Vogt (2006), Massarani (2002) Massarani, Moreira e Brito (2002), Werthein e Cunha (2009) e Munhoz, Hattge e Zanotelli (2013). Em todos eles, o cerne das reflexões envolve analisar, discutir e principalmente fomentar ações e processos que envolvam a divulgação da ciência e da tecnologia ao grande público, em espaços formais e não formais. Como afirma Sánchez Mora (2003, p. 9): "O problema da divulgação da ciência é de grande complexidade. Enfrentá-lo é tão difícil quanto visar um alvo em movimento”. A própria nomenclatura do termo (divulgação - popularização - alfabetização - comunicação - científica) é alvo de discussão (SASSERON, CARVALHO, 2011).

Como se espera de uma boa refeição, após Entrada, seguida de primeiro prato (primeiro capítulo), do Segundo prato (segundo capítulo) e das Bebidas à parte (terceiro capítulo), temos a sobremesa como quarto capítulo: "Sobremesa sabor de ciência (e de sociedade) - de Brillat-Savarin à gastronomia molecular, passando pela culinária futurista". Um histórico desde o tempo em que a Gastronomia se esforçava para reivindicar espaço enquanto área científica até sua íntima e presente relação com a Química, na produção/desenvolvimento de novos produtos, pratos e receitas, antes impensáveis, é o centro das discussões. A culinária futurista, da qual a gastronomia molecular é uma representante, os experimentos e as receitas secretas (de chocolate, por exemplo) destacam as peculiaridades que associam ciência e culinária. 
Finalizamos a resenha dessa obra em um momento complexo. No mesmo instante em que a comunidade científica se esforça na realização de pesquisas envolvendo a compreensão e a busca da cura de diversas doenças, discutimos a preocupante proliferação desenfreada de notícias falsas. As famosas fake news, via internet e (principalmente) pelos aplicativos de trocas de mensagens, presentes em nossos smartphones, alastram boatos em mensagens que, por exemplo, pregam a não vacinação como um ato saudável.

Triste ironia do progresso científico: algo fruto do desenvolvimento da Ciência utilizado como meio de divulgar ideias equivocadas. Afirmações pseudocientíficas, quando propagadas, "adquirem" status científico, e isso é um problema grave. A preocupação com os investimentos (e esforços) públicos com o intuito de propiciar uma educação/cultura científica de qualidade é real, urgente e necessária, como problematizado no documento Ensino de ciências: o futuro em risco, da Organização das Nações Unidas para a Educação, a Ciência e a Cultura (UNESCO) (2005, p. 3):

[...] o ensino de Ciências é fundamental para a população não só ter a capacidade de desfrutar dos conhecimentos científicos e tecnológicos, mas para despertar vocações, a fim de criar estes conhecimentos. O ensino de Ciências é fundamental para a plena realização do ser humano e a sua integração social. Continuar aceitando que grande parte da população não receba formação científica e tecnológica de qualidade agravará as desigualdades do país e significará seu atraso no mundo globalizado. Investir para constituir uma população cientificamente preparada é cultivar para receber de volta cidadania e produtividade, que melhoram as condições de vida de todo o povo.

A obra que resenhamos possibilita e potencializa ações de reflexão a respeito da Ciência, dos seus avanços presentes em nossas ações cotidianas, das percepções públicas relacionadas à ciência e também aos cientistas, bem como as problemáticas envolvidas em seus processos de divulgação. Saímos desse restaurante científico satisfeitos e recomendamos aos leitores interessados na temática que o visitem. Discutir a ciência é o prato principal, e a companhia de Massimiano Bucchi torna essa uma experiência intelectual agradável.

\section{Notas}

1 Dezesseis títulos compõem essa coleção. Além do livro que resenhamos, foram publicados $O$ Sol morto de rir (2008); A extinção dos tecnossauros (2008); Ciência: use com cuidado (2008); O gozo intelectual (2009); Inventando milhões (2009); Dez teorias que comoveram o mundo (2009); Kluge (2010); Borges e a mecânica quântica (2011); Superstição (2011); O sonho de Einstein (2011); A fórmula secreta (2012); Almanaque (2013); Os remédios da vovó (2013); Um esqueleto incomoda muita gente (2013); e O jogador científico: por que perdemos no pôquer, na loteria, na roleta... (2015). 


\section{Referências}

ANJOS, Francisco Antônio dos; CABRAL, Silvia Regina; HOSTINS, Regina Celia Linhares. O cenário da formação superior em Gastronomia no Brasil: uma reflexão da oferta. Revista Hospitalidade, São Paulo, v. 14, n. 1, p. 1-21, ago. 2017.

BUCCHI, Massimiano. O frango de Newton: a ciência na cozinha. Tradução de Regina Célia da Silva. Campinas: Editora da Unicamp, 2015.

MASSARANI, Luisa (org.). O pequeno cientista amador: a divulgação científica e o público infantil. Rio de Janeiro: Casa da Ciência - Centro Cultural de Ciência e Tecnologia da Universidade Federal do Rio de Janeiro, 2002.

MASSARANI, Luisa; MOREIRA, Ildeu de Castro; BRITO; Fátima. Ciência e público: caminhos da divulgação científica no Brasil. Rio de Janeiro: Casa da Ciência - Centro Cultural de Ciência e Tecnologia da Universidade Federal do Rio de Janeiro, Fórum de Ciência e Cultura, 2002.

MUNHOZ, Angélica Aier; HATTGE, Morgana Domenica; ZANOTELLI, Allissara. Acerca da alfabetização científica: representações e discursos no cotidiano de uma escola. Imagens da Educação, Maringá, v. 3, n. 3, p. 01-09, 2013.

RUBIM, Rebeca Elster; REJOWSKI, Mirian. O ensino superior da gastronomia no Brasil: análise da regulamentação, da distribuição e do perfil geral de formação (2010-2012). Turismo-Visão e Ação, v. 15, n. 2, p. 166-184, 2013.

SÁNCHEZ MORA, Ana Maria. A divulgação da ciência como literatura. Rio de Janeiro: Casa da Ciência - Centro Cultural de Ciência e Tecnologia da Universidade Federal do Rio de Janeiro, Editora UFRJ, 2003.

SASSERON, Lúcia Helena; CARVALHO, Anna Maria Pessoa de. Alfabetização científica: uma revisão bibliográfica. Investigações em Ensino de Ciências, Porto Alegre, v. 16, n. 1, p. 59-77, 2011.

ORGANIZAÇÃO DAS NAÇÕES UNIDAS PARA A EDUCAÇÃO, A CIÊNCIA E A CULTURA - UNESCO. Ensino de ciências: o futuro em risco. 2005. Disponível em: http://unesdoc.unesco. org/images/0013/001399/139948por.pdf. Acesso em: 02 jun. 2018.

VOGT, Carlos (org.). Cultura científica: desafios. São Paulo: Editora da Universidade de São Paulo, 2006.

WERTHEIN, Jorge; CUNHA, Célio (org.). Ensino de Ciências e desenvolvimento: o que pensam os cientistas. Brasília: UNESCO; Instituto Sangari, 2009. 